\title{
Avaliação da eficácia do fipronil em Rhipicephalus (Boophilus) microplus em tratamentos consecutivos
}

\author{
[Evaluating the effectiveness of fipronil in Rhipicephalus (Boophilus) microplus \\ in consecutive treatments] \\ A.P. Souza $^{1}$, F. Paim ${ }^{2}$, V. Bellato ${ }^{1}$, A.A. Sartor ${ }^{1}$, A.B. Moura ${ }^{1}$, L.D. Rosa ${ }^{2}$, D.J. Miquelluti ${ }^{1}$ \\ ${ }^{1}$ Centro de Ciências Agroveterinárias - Universidade do Estado de Santa Catarina - UDESC - Lages, SC \\ ${ }^{2}$ Aluna de pós-graduação - Universidade do Estado de Santa Catarina - UDESC - Lages, SC
}

\begin{abstract}
RESUMO
A realização deste trabalho teve como objetivo avaliar a eficácia do fipronil em Rhipicephalus (Boophilus) microplus, durante e após 14 tratamentos, no período de dezembro de 2006 a abril de 2009. O experimento foi realizado em uma propriedade rural do município de Lages, SC, utilizando-se 20 bovinos mestiços charolês mantidos em campo nativo, naturalmente infestados com $R$. (B.) microplus. A cada 14 dias, foram realizadas contagens das fêmeas de carrapato, maior ou igual a $4,5 \mathrm{~mm}$. Os animais foram tratados com fipronil $1 \mathrm{mg} / \mathrm{kg}$ via pour on, quando a média do número de carrapatos foi igual ou superior a 40 fêmeas. Ao final do experimento, para análise da eficácia do fipronil $1 \%$, foi realizado o teste de estábulo, utilizando 10 animais infestados com larvas provenientes de teleóginas coletadas de bovinos da propriedade. Os animais foram randomizados, de acordo com a produção inicial de teleóginas, estabelecendo-se dois grupos: controle $(n=5)$ e tratado $(n=5)$. A redução da média do número de fêmeas de $R$. (B.) microplus nas contagens após tratamentos foi de $100 \%$ nos três primeiros, com um leve declínio até o sexto tratamento. No sétimo tratamento a redução foi de $91,3 \%$. Ao final do experimento a eficácia do fipronil $1 \%$, avaliada pelo teste de estábulo, na redução do número de teleóginas, foi de $79,3 \%$. A porcentagem média de inibição de reprodução calculada foi de $22,47 \%$. Concluiu-se que, após seis tratamentos com fipronil, média de um a cada 2,7 meses, o princípio ativo deve ser substituído e que, após 14 tratamentos, o $R$. (B.) microplus adquiriu resistência parcial a esse carrapaticida.
\end{abstract}

Palavras-chave: carrapato, acaricida, resistência

\begin{abstract}
This study aimed to evaluate the effectiveness of fipronil in Rhipicephalus (Boophilus) microplus during and after 14 treatments from December 2006 to April 2009. The experiment was performed on a rural property in the city of Lages/SC, using 20 crossbred Charolais cattle maintained on open pasture naturally infected with R. (B.) microplus. Every 14 days, tick counts of the females greater than or equal to $4.5 \mathrm{~mm}$ were conducted. When tick counts averaged 40 females or more the animals were treated with applications of a $1 \%$ applied to the dorsal formulation of fipronil $1 \mathrm{mg} / \mathrm{kg}$. At the end of the experiment, barn testing was performed on 10 animals infested with larvae of the Engorging females collected from the cattle on the property, for analysis of the effectiveness of $1 \%$ fipronil. The animals were randomized according to the initial production of Engorging females, establishing five animals in the control group and five in the treated group. The reduction in the average number of females of $\mathrm{R}$. (B.) microplus was $100 \%$ during the first three treatments, with a slight decline up to the sixth treatment. On the seventh treatment the reduction was $91.3 \%$. At the end of the experiment the effectiveness of $1 \%$ fipronil for reducing the number of ticks was $79.3 \%$, assessed by the barn testing. The average percentage of inhibition of reproduction was calculated at $22.47 \%$. It was concluded that after six treatments with fipronil, with an average of one treatment every 2.7 months, there must be a change in the active ingredient and that after 14 treatments $\mathrm{R}$. (B.) microplus acquired partial resistance to this acaricide.
\end{abstract}

Keywords: tick, acaricide, resistance

Recebido em 23 de outubro de 2012

Aceito em 20 de agosto de 2013

E-mail: a2aps@cav.udesc.br 


\section{INTRODUÇÃO}

O controle do Rhipicephalus (Boophilus) microplus tem sido feito principalmente com o uso de carrapaticidas. No entanto, o surgimento de populações de resistentes aos acaricidas vem sendo crescente em todas as regiões onde o parasito encontra condições favoráveis ao seu desenvolvimento (Farias et al. 2008). No Brasil, existem populações resistentes aos diferentes acaricidas, em vários Estados (Fernandes, 2001; Souza et al., 2003; Campos Junior e Oliveira, 2005; Andreotti et al., 2011; Veiga et al., 2012).

Os fenilpirazois foram desenvolvidos na década de 1980 e introduzidos no mercado por volta dos anos 90, com indicação para uso na agricultura e na medicina veterinária (Tanner et al., 1997; Chandler et al., 2004). O mecanismo de ação do fipronil ocorre pelo antagonismo do receptor GABA (ácido $\gamma$-aminobutírico), bloqueando os canais de cloro (Rauh et al., 1990; Postal et al., 1995), interferindo na neuromodulação, levando à morte por hiperexcitação (Tanner et al., 1997).

Cepas de $R$. (B.) microplus resistente ao fipronil foram detectadas por Coure et al. (2007), no Uruguai, usando teste de estábulo, e por CastroJaner et al. (2010a), através de testes in vitro por imersão de adultos (TIA) e de larvas (TIL). No Brasil, Castro-Janer et al. (2010b), utilizando o TIL, confirmaram a resistência ao fipronil de cepas desse ixodíeo provenientes do Rio Grande do Sul, Mato Grosso do Sul e São Paulo.

De uma maneira geral, pode-se afirmar que os relatos de resistêcia do $R$. (B.) microplus têm sido com base em testes in vitro e in vivo e no histórico da utilização dos carrapaticidas, e que, na grande maioria das vezes, os criadores não tinham informações precisas para uma efetiva análise. Assim, a realização deste trabalho teve como objetivo avaliar o efeito do fipronil na redução do número de fêmeas desse ixodídeo em bovinos mantidos em campo nativo durante 28 meses e, após esse período, verificar a eficácia por meio de teste de estábulo.

\section{MATERIAL E MÉTODOS}

O experimento foi realizado no período de dezembro de 2006 a abril de 2009, em uma propriedade rural localizada a $25 \mathrm{~km}$ de Lages, SC, latitude $27^{\circ} 49^{\prime} 611^{\prime \prime}$ Sul, longitude
50³2’303'” Oeste, 927 metros de altitude. Nessa propriedade nunca tinha sido utilizado fipronil para o controle do $R$. (B.) microplus, e os bovinos eram criados em campo nativo, com uma lotação de 0,4 cabeças/hectare.

Foram utilizados 20 bovinos cruza charolês que, no início do experimento, tinham aproximadamente sete meses de idade. A cada 14 dias, fêmeas de $R$. (B.) microplus com tamanho igual ou superior a $4,5 \mathrm{~mm}$ foram contadas no lado direito do corpo de cada animal e o resultado multiplicado por dois. Todos os bovinos recebiam o mesmo manejo e, quando a média do número de carrapatos era superior a 40 , todos os animais da propriedade eram tratados com fipronil, $1 \mathrm{mg} / \mathrm{kg}$ por via dorsal. Para a comparação da eficácia do carrapaticida entre cada ano experimental, os dados foram transformados por arco-seno raiz submetidos ao Teste t.

Ao final dos 28 meses experimentais, após 30 dias sem aplicação de carrapaticida, foram coletadas aproximadamente 100 teleóginas, as quais foram acondicionadas em Placa de Petri identificadas e mantidas em câmara climatizada regulada à temperatura de $27 \pm 1^{\circ} \mathrm{C}, 80 \pm 10 \%$ de umidade relativa e escotofase, para postura e obtenção de larvas, visando às infestações de bovinos para avaliação da eficácia do fipronil em teste de estábulo.

Para realização do teste de estábulo, foram utilizados 10 bovinos da raça holandês, com aproximadamente $200 \mathrm{~kg}$ de peso corporal, que foram alojados individualmente em baias de piso ripado. Os animais foram infestados com aproximadamente 2.500 larvas, com idade entre 10 a 21 dias, nos dias: $-24-21,-19,-17,-14,-12$, $-10,-7,-5,-3,-1$, considerando o dia 0 (zero) como o dia do tratamento. Posteriormente esses animais foram randomizados, com base na produção de teleóginas dos três primeiros dias, estabelecendo-se cinco animais para o grupo Controle e cinco animais para o Tratado com fipronil a $1 \%, 1 \mathrm{mg} / \mathrm{kg}$, uso dorsal.

Diariamente foram realizadas coletas totais de carrapatos desprendidos do corpo dos animais a partir do dia -3 até o dia +23 do ensaio. Das teleóginas coletadas, dez pertencentes a 
cada grupo, foram pesadas coletivamente, acondicionadas e incubadas conforme já descrito, para realização das posturas e análise da viabilidade dos ovos. Após 18 dias, os ovos foram pesados e colocados dentro de tubos de ensaio identificados, retornando à incubação e, posteriormente, foi estimada visualmente a porcentagem de eclosão das larvas. Os dados da redução do número médio de teleóginas desprendidas, antes e após o tratamento, foram submetidos à análise estatística, pelo Teste t, considerando variáveis equivalentes.

Para o cálculo da eficácia do tratamento, na redução do número de teleóginas, foram comparadas às médias das recuperadas dos animais tratados com as do grupo controle, em que foi empregada a seguinte fórmula:

onde:

$$
\left[1-\left(\mathrm{T}_{\mathrm{a}} \times \mathrm{C}_{\mathrm{b}}\right) /\left(\mathrm{T}_{\mathrm{b}} \times \mathrm{C}_{\mathrm{a}}\right)\right] \times 100
$$

$\mathrm{T}_{\mathrm{a}}=$ número médio de teleóginas recuperadas dos animais tratados após o tratamento (dias +1 a $+23)$;

$\mathrm{T}_{\mathrm{b}}=$ número médio de teleóginas recuperadas dos animais tratados nos 3 dias anteriores ao tratamento;

$\mathrm{C}_{\mathrm{a}}=$ número médio de teleóginas recuperadas dos animais controles período após o tratamento $($ dias +1 a +23$)$;

$\mathrm{C}_{\mathrm{b}}=$ número médio de teleóginas recuperadas dos animais controles nos três dias anteriores ao dia do tratamento.

O Índice de reprodução (IR) foi calculado para cada grupo em cada um dos 23 dias de avaliação utilizando a seguinte fórmula:

$$
\mathrm{IR}=\frac{\text { Média do peso da massa de ovos x \% de eclosão dos ovos }}{\text { Média do peso das teleóginas }} 20.000
$$

Para a determinação da eficácia nas teleóginas de $R$. (B.) microplus colhidas durante o teste de estábulo, foi empregada a seguinte fórmula:

$$
\% \text { de inibição de reprodução }=\frac{(\text { IR controle }- \text { IR tratado })}{\text { IR controle }} \times 100
$$

O critério utilizado para considerar o carrapaticida eficaz foi o valor mínimo de $95 \%$, conforme a legislação vigente para obtenção do registro de acaricidas junto ao Ministério da Agricultura e Abastecimento no Brasil (Brasil, 1997).

\section{RESULTADOS E DISCUSSÃO}

Na Figura 1 está expressa a média do número de fêmeas ingurgitadas de $R$. (B.) microplus, contadas a cada 14 dias, em bovinos tratados com fipronil, quando a média era superior a 40 , no período de dezembro de 2006 a abril de 2009. Observou-se uma redução do número médio de carrapatos nos meses de abril a novembro de 2007, sem que houvesse tratamentos acaricidas; provavelmente, devido às condições climáticas desfavoráveis - resultados semelhantes aos observados por Souza et al. (1988) em estudos sobre a variação sazonal desse ixodídeo no Planalto Catarinense. Entretanto, em 2008, somente observou-se redução por fatores epidemiológicos, no mês de setembro, provavelmente por diferenças climáticas. As infestações que resultaram em tratamentos nos meses de julho e agosto de 2008 sugerem a necessidade de se realizarem novos estudos epidemiológicos, considerando que, quando foram realizados tais estudos, as infestações nessas épocas eram baixas.

A redução da média do número de fêmeas ingurgitadas de R. (B.) microplus foi de $100 \%$ nos três primeiros tratamentos, com um leve declínio até o sexto tratamento $(98,1 \%)$. No sétimo, a redução foi de $91,3 \%$, sendo realizado em média, durante esse período, um tratamento a cada 2,7 meses (Fig. 2). Em janeiro de 2009, após o primeiro tratamento do mês, ocorreu uma forte chuva e a eficácia na redução do número de $R$. (B.) microplus, na avaliação 14 dias após o tratamento, foi de $60,8 \%$. Nessa contagem os animais ainda permaneceram com uma infestação média de 40,3 fêmeas com mais de $4,5 \mathrm{~mm}$, necessitando de novo tratamento. A partir de novembro de 2008, a frequência de tratamentos aumentou (um a cada 1,5 meses, mesmo desconsiderando o segundo tratamento em janeiro), diminuindo a eficácia na redução do 
número de ixodídeos e, consequentemente, levando à suspeita de resistência ao carrapaticida. Considerando o número de tratamentos necessários para o controle do $R$. (B.) microplus por ano experimental, ou seja, de dezembro a novembro, foram realizados três tratamentos no primeiro ano, sete no segundo e três no período de janeiro a abril de 2009, desconsiderando um tratamento em janeiro, cujo resultado apresentou falha atribuída a forte chuva, logo após esse tratamento.

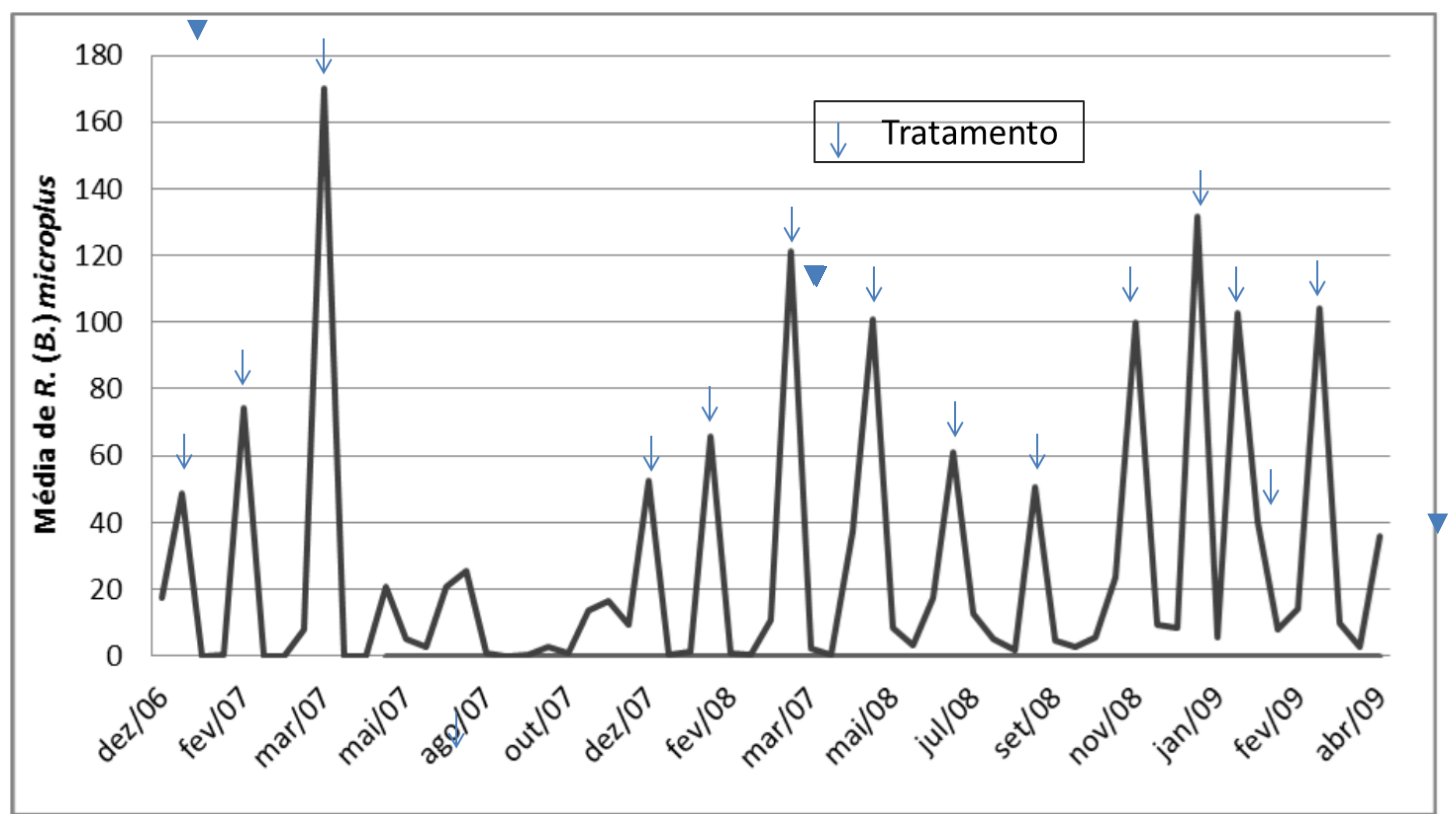

Figura 1. Média do número de fêmeas ingurgitadas de Rhipicephalus (Boophilus) microplus, verificada a cada 14 dias, em bovinos naturalmente infestados e tratados com fipronil quando a média era superior a 40, no período de dezembro de 2006 a abril de 2009, em Lages, Santa Catarina, Brasil.

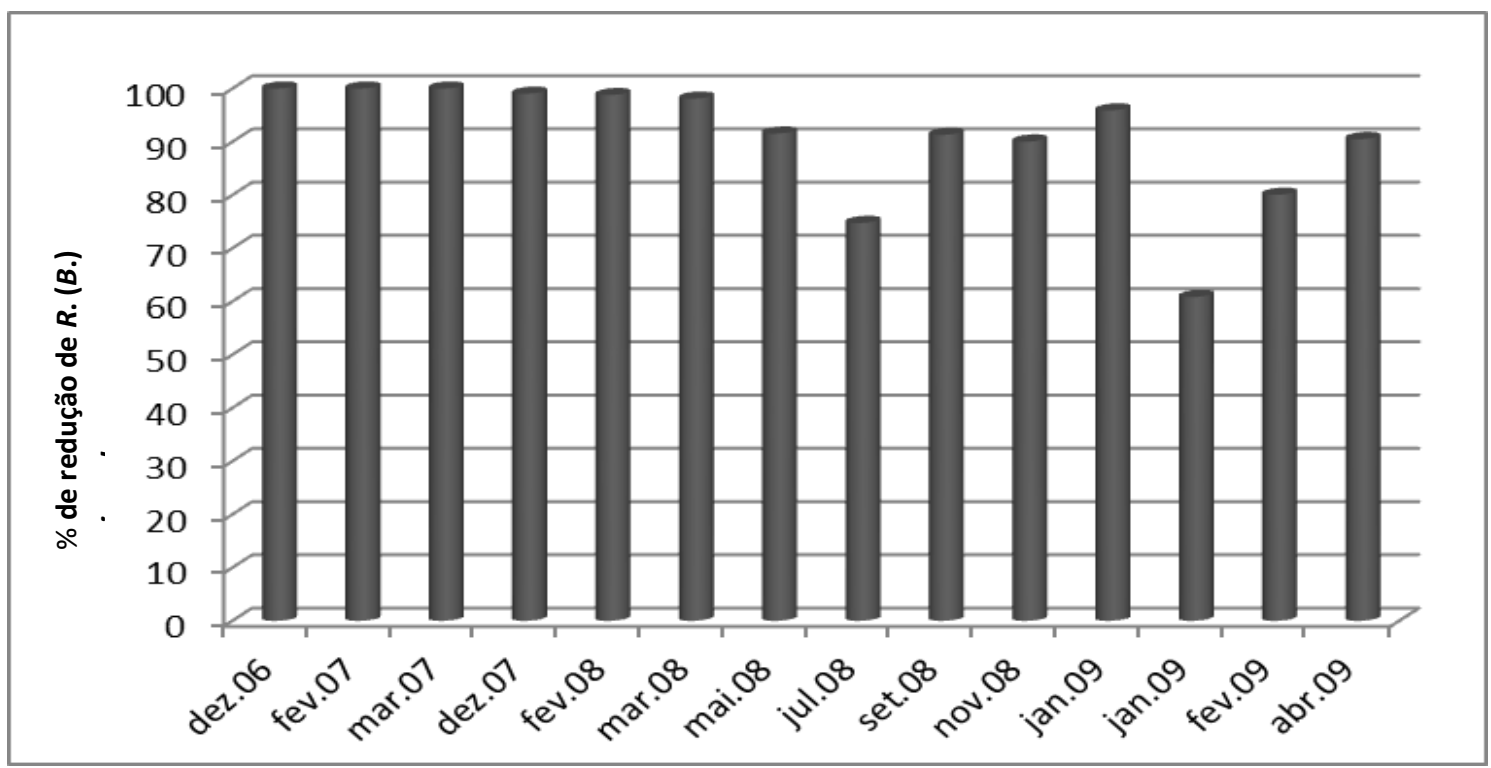

Figura 2. Porcentagem de redução do número de fêmeas ingurgitadas de Rhipicephalus (Boophilus) microplus, em bovinos naturalmente infestados, 14 dias após cada tratamento com fipronil no período de dezembro de 2006 a abril de 2009, em Lages, Santa Catarina, Brasil. 
Verificou-se que a média da redução do número de carrapatos no primeiro ano do experimento foi de $99,8 \%$, no segundo, de $90,8 \%$ e, no terceiro, $81,8 \%$, apresentando diferença estatística $(\mathrm{P}<0,05)$ entre o primeiro ano do experimento e os demais.

O número médio de teleóginas de $R$. (B.) microplus, recuperadas de bovinos, nos dias -3 a +23, em teste de estábulo, consta na Figura 3. Na avaliação do teste de estábulo, o número médio de teleóginas recuperadas dos animais nos dias 3 a -1 no grupo controle foi 95,5 e, no grupo tratado, 98,3, não apresentando diferença estatística (P>0,05). Após a medicação (dias +1 $a+23$ ), foi 43,5 no grupo controle e 204,5 no grupo tratado, apresentando diferença estatística $(\mathrm{P}<0,05)$.

A eficácia do fipronil a 1\%, após 14 tratamentos durante o experimento, na redução do número de fêmeas ingurgitadas, foi de 79,3\%.

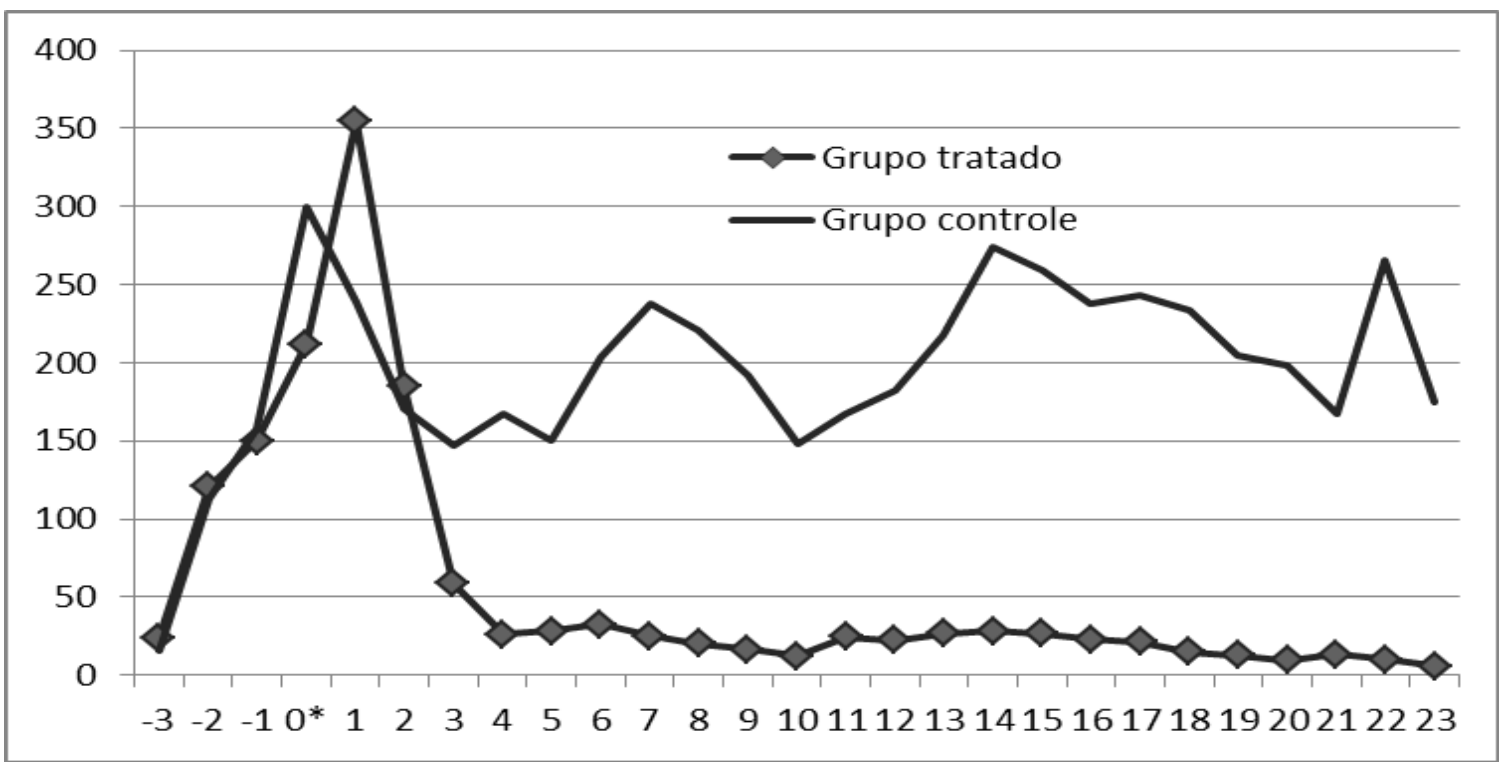

Figura 3. Número médio de teleóginas de Rhipicephalus (Boophilus) microplus, recuperadas de bovinos, nos dias -3 a +23 no grupo controle e no tratado com fipronil, em teste de estábulo.

*Dia do tratamento.

Além da eficácia calculada, (79,3\%) considerando a queda das teleóginas, inferior à recomendada para uso do produto, a porcentagem média de inibição de reprodução foi de apenas $22,47 \%$, evidenciando viabilidade da maioria dos ovos. A redução da eficácia do fipronil, após 28 meses de uso (14 tratamentos), leva a inferir a ocorrência de resistência parcial, observada a partir do sexto tratamento nos bovinos, da população de $R$. (B.) microplus. Resistência ao fipronil foi detectada, no Uruguai, por Coure et al. (2007), usando teste de estábulo, e por Castro-Janer et al. (2010a) por testes in vitro por imersão de adultos (TIA) e imersão de larvas (TIL). No Brasil Castro-Janer et al. (2010b), utilizando o TIL, confirmaram a resistência ao fipronil de cepas de $R$. (B.) microplus provenientes do Rio Grande do Sul, Mato Grosso do Sul e São Paulo. Entretanto, deve-se considerar que a maioria dos estudos foi realizada utilizando técnicas in vitro, e os dados, coletados por suspeita de ineficácia, não apresentavam um histórico preciso da utilização do carrapaticida.

\section{CONCLUSÕES}

Após seis tratamentos com fipronil para o controle de Riphicephalus (Boophilus) microplus, em média um a cada 2,7 meses, o princípio ativo deve ser substituído. O Riphicephalus (Boophilus) microplus adquire resistência parcial ao fipronil, quando utilizado, em média, um tratamento bimestral, em 14 tratamentos consecutivos. 


\section{REFERÊNCIAS}

ANDREOTTI, R.; GUERRERO, F.D.; SOARES, M.A. et al. Acaricide resistance of Rhipicephalus (Boophilus) microplus in State of Mato Grosso do Sul, Brazil. Rev. Bras. Parasitol. Vet., v.20, p.127-133, 2011.

BRASIL. Ministério da Agricultura e do Abastecimento. Secretaria de Defesa Agropecuária. Portaria $\mathrm{n}^{\circ}$ 48, de 12 de maio de 1997. Regulamento Técnico para Licenciamento elou Renovação de Licença de Produtos Antiparasitários de uso Veterinário. Disponível em http://extranet.agricultura.gov.br/sislegisconsulta/consultarLegislacao.do?operacao=visua lizar\&id=2493 Acessado em 8 novembro, 2010.

CAMPOS JUNIOR, D.A.; OLIVEIRA, P.R Avaliação in vitro da eficácia de acaricidas sobre Boophilus microplus (Canestrini, 1887) (Acari: Ixodidae) de bovinos no município de Ilhéus, Bahia, Brasil. Cienc. Rural, v.3, p.1386-1392, 2005.

CASTRO-JANER, E.; RIFRAN, L.; GONZÁLEZ, P. et al. Riphicephalus (Boophilus) microplus (Acari:Ixodidae) resistance to fipronil in Uruguay evaluated by in vitro bioassays. Vet. Parasitol., v.169, p.172-177, 2010a.

CASTRO-JANER, E.; MARTINS, J.R.; MENDES, M.C. et al. Diagnoses of fipronil resistance in Brazilian cattle ticks Riphicephalus (Boophilus) microplus using in vitro larval bioassays. Vet. Parasitol., v.173, p.300-306, 2010 b.

CHANDLER, G.T.; CARY, T.L.; VOLZ, D.C. et al. Fipronil effects on estuarine copepod (Amphiascus tenuiremis) development, fertility, and reproduction: a rapid life-cycle assay in 96well microplate format. Enviromen. Toxicol. Chemistry, v.23, p.117-124, 2004.

COURE, U.; TRELLES, A.; SANCHÍS, J. et al. Primer diagnóstico de resistencia al Fipronil en la garrapata común del Ganado Boophilus microplus Vet., v.42, p.35-41, 2007.
FARIAS, N.A.; RUAS, J.L.; SANTOS, T.R.B. Análise da eficácia de acaricidas sobre o carrapato Boophilus microplus, durante a última década, na região sul do Rio Grande do Sul. Cienc. Rural, v.38, p.1700-1704, 2008.

FERNANDES, F.F. Toxicological effects and resistance to pyrethroids in Boophilus microplus from Goiás, Brazil. Arq. Bras. Med. Vet. Zootec., v.53, p.538-543, 2001.

POSTAL, J.M.R.; JEANNIN, P.C.; CONSALVI, P.J. Field efficacy of a mechanical pump spray formulation containing $0,25 \%$ fipronil in the treatment and control of flea infestation and associated dermatological signs in dogs and cats. Vet. Dermatol., v.6, p.153-158, 1995.

RAUH, J.J.; LUMMIS, S.C.R.; SATTELLE, D.B. Pharmacological and biochemical properties of insect GABA receptors. Trends in Pharmacol. Sci., v.11, p.325-329, 1990.

SOUZA, A.P.; GONZALES, J.C.; RAMOS, C.I. et al. Variação Sazonal de Boophilus microplus no Planalto Catarinense. Pesq. Agropec. Bras., v.23, p.627-630, 1988

SOUZA, A.P.; SARTOR A.A.; BELLATO V.; PERUSSOLO, S. Eficácia de carrapaticidas em rebanhos de bovinos leiteiros de municípios da região Centro-Sul do Paraná. Rev. Cienc. Agrovet., v.2, p.245-250, 2003.

TANNER, P.A.; MEO, N.J.; SPARER, D. et al. Advances in the treatment of heartworm, fleas and ticks. Can. Pract., v.22, p.40-47, 1997.

VEIGA, L.P.H.N.; SOUZA, A.P.; BELLATO, V. et al. Resistance to cypermethrin and amitraz in Rhipicephalus (Boophilus) microplus on the Santa Catarina Plateau, Brazil. Rev. Bras. Parasitol. Vet., v.21, p.133-136, 2012. 